\title{
Anemometer Modified II
}

\author{
Kern E. Kenyon \\ North Lane, Del Mar, USA
}

Correspondence to: Kern E. Kenyon, kernken@aol.com

Keywords: Standard Anemometer, Cups Modified to Blades

Received: June 26, $2021 \quad$ Accepted: August 2, $2021 \quad$ Published: August 5, 2021

Copyright $\odot 2021$ by author(s) and Scientific Research Publishing Inc.

This work is licensed under the Creative Commons Attribution International License (CC BY 4.0).

http://creativecommons.org/licenses/by/4.0/

\section{(c) (i) Open Access}

\section{ABSTRACT}

A commercial anemometer was modified by replacing the four cups with four identical two-dimensional blades, each with a circular arc side and a flat side. The flat sides are fixed to four arms radiating from a pivot so that they are parallel to the wind direction. The rounded sides all point in the same direction around a circle. When the wind blows, there is a lift force on the rounded side of each blade and they unite in causing rotation about the pivot with the curved sides leading. The more blades the faster the rotation is a prediction.

\section{INTRODUCTION}

Earlier a commercial anemometer was obtained and modified by replacing the cups with solid cones [1]. Four hemi-spherical cups were replaced by two double cones. Each double cone consisted of two cones of equal bases, joined base to base, but their altitudes were significantly different. They were identical but faced in opposite directions when attached to a frame which was placed horizontally on the vertical pivot. As the fan blew air straight at them, they rotated in the horizontal plane with the shorter altitude cones leading and the longer cones trailing.

What drove the rotation in this case was a net reaction force on each double cone caused by the air accelerating and decelerating along the solid surfaces, in accordance with Newton's third law [2]. This modification of the anemometer was designed in part to illustrate the driving force, which is not well-known and not obvious a priori. However, through evolution fish have been using this method of enhancing locomotion for millions of years.

In the second modification of an anemometer presented here a better appreciated force, lift on the wing of a bird or plane, is used in a way that is probably new and has not come into common practice. Four cups are replaced by four sticks of equal length. Each stick has a flat side and a rounded one and it is oriented on an arm of the frame such that the lift force felt on the rounded side by air passing by is coordinated adding impetus to the rotation.

\section{METHOD}

To obtain a confirmation of the above conjecture only two half rounded sticks were tried out for 
blades and attached to two opposite arms of the four arm frame that rotates when placed on the pivot. In mounting the two sticks the flat sides were held perpendicular to the plane of rotation and the two rounded sides were pointed in opposite directions. Then the base of the pivot was mounted on a vertical board and a fan was brought up close to the blades. There were three speed settings on the fan, which caused air to blow straight at the edge of the blades.

For all three settings of the fan it was found that once started the two bladed propeller would never stop on its own. Also the sense of rotation was such that the rounded sides were leading as expected. Then follows the prediction: if four blades had been used instead of two, the rotation rate would have been faster for the given fan setting. This prediction has not yet been confirmed.

In a recent model of the lift force on a circular arc wing a formula for the lift force was produced in terms of the parameters of the problem [2]. The same could be done for the double cone modification of the anemometer, but that has not occurred yet. Whether a force formula exists for the standard cup anemometer is not known to me.

\section{DISCUSSION}

Considering the rather complicated shape of the blades of modern wind mills that produce electricity, it seems doubtful that the wind force on those blades could be expressed in simple terms for a given wind speed. Also It is not clear from observing the operational wind mills around the country if the optimum, or most efficient, number of blades to use is known or not.

\section{CONCLUSION}

By a particular and unusual selection of the shape and orientation of the cups of a standard anemometer, the propeller can be powered by the lift force on each blade when the wind blows past it. The main features of the two-dimensional shapes are a circular side and a flat side, which is held parallel to the wind direction. Curved sides all point in the direction of rotation. Faster rotation should occur for a given wind as the number of blades increases.

\section{ACKNOWLEDGEMENTS}

Mark Welle made a better set of circular arc blades for the trial runs than I had available before. Comments by the Reviewer were helpful.

\section{CONFLICTS OF INTEREST}

The author declares no conflicts of interest regarding the publication of this paper.

\section{REFERENCES}

1. Kenyon, K.E. (2019) Anemometer Modified. Natural Science, 11, 41-44. https://doi.org/10.4236/ns.2019.112006

2. Kenyon, K.E. (2021) Lift on a Low Speed Circular Arc Wing due to Air Compression. Natural Science, 13, 88-90. https://doi.org/10.4236/ns.2021.133008 